\title{
Meal Data Completion Status
}

National Cancer Institute

\section{Source}

National Cancer Institute. Meal Data Completion Status. NCI Thesaurus. Code C162332.

A term used to describe the state or condition of the completeness of the meal data. 